\title{
EDUCAÇÃO EM SAÚDE NA SALA DE ESPERA: EXPECTATIVA DAS MÃES FRENTE À CONDIÇÃO CRÔNICA DO FILHO
}

Sabrina Mara Fighera', Hilda Maria Barbosa de Freitas², Silomar Ilha ${ }^{3}$, Claudia Zamberlan ${ }^{4}$, Maristel Kasper Grando, Juliana Silveira Colomé ${ }^{6}$

RESUMO: O estudo teve por objetivo compreender a expectativa das mães que participam de um Grupo de Sala de Espera frente à condição crônica do filho. Trata-se de uma pesquisa exploratória, descritiva, de caráter qualitativo e desenvolvida entre abril e maio de 2011 com 12 mães de crianças/adolescentes hospitalizados. Os dados coletados por meio de entrevista semiestruturada resultaram nas categorias: Adaptando-se a condição crônica do filho; União familiar frente à condição crônica do filho; Condição crônica: alterando as rotinas no contexto familiar; Sala de espera: troca de experiência e cuidado de enfermagem. Evidenciou-se que o alicerce para o enfrentamento da condição crônica do filho, a fim de superar dificuldades, está na união familiar. Assim, compreende-se que a educação em saúde, desenvolvida com grupos de convivência, contribui para melhoria na qualidade de vida das famílias de pessoas com condição crônica. PALAVRAS-CHAVE: Família; Criança; Adolescente; Doença crônica; Enfermagem.

\section{HEALTH EDUCATION IN THE WAITING ROOM: MOTHERS' EXPECTATIONS IN THE FACE OF THEIR CHILD'S CHRONIC CONDITION}

ABSTRACT: The study aimed to investigate the expectations of mothers participating in a Waiting Room group, in the face of their child's chronic condition. It is exploratory, descriptive, qualitative research, undertaken between April and May 2011 with 12 mothers of hospitalized children/adolescents. The data, collected through semi-structured interviews, resulted in the categories: Adapting to the child's chronic condition; Family unit in the face of the child's chronic condition; Chronic condition: altering routines in the family context; Waiting Room: exchange of experiences and nursing care. It was evidenced that the basis for facing the child's chronic condition, so as to overcome difficulties, is in the family unit. Thus, it is understood that health education, carried out in centers of connivance and leisure, contributes to improvement of quality of life of families of persons with a chronic condition.

KEYWORDS: Family; Child; Adolescent; Chronic illness; Nursing.

\section{EDUCACIÓN EN SALUD EN LA SALA DE ESPERA: EXPECTATIVA DE LAS MADRES DELANTE DE LA CONDICIÓN CRÓNICA DEL HIJO}

RESUMEN: El estudio tuvo por objetivo comprender la expectativa de las madres que participan de un grupo de Sala de Espera delante de la condición crónica del hijo. Es una investigación exploratoria, descriptiva, de carácter cualitativo y desarrollada entre abril y mayo de 2011 con 12 madres de niños/adolescentes hospitalizados. Los datos obtenidos por medio de entrevista semiestructurada resultaron en las categorías: Adaptándose a la condición crónica del hijo; Unión familiar delante de la condición crónica del hijo; Condición crónica: cambiando las rutinas en el contexto familiar; Sala de espera: cambio de experiencia y cuidado de enfermería. Se constató que el fundamento para el afrontamiento de la condición crónica del hijo, para la superación de las dificultades, está na unión familiar. Así, se comprende que la educación en salud, desarrollada con grupos de convivencia, contribuye para mejoría en la cualidade de vida de las familias de personas con condición crónica.

PALABRAS CLAVE: Familia; Niño; Adolescente; Enfermedad crónica; Enfermería.

\footnotetext{
${ }^{1}$ Enfermeira responsável técnica da Clínica de Anestesia de Santa Maria. Santa Maria - RS.

${ }^{2}$ Enfermeira. Doutoranda em Enfermagem pelo DINTER Novas Fronteiras UNIFESP/UFRJ/UFSM. Professora do Centro Universitário Franciscanbo - UNIFRA. Membro do Grupo de Estudos e Pesquisa em Empreendedorismo Social da Enfermagem e Saúde - GEPESES. ${ }^{3}$ Enfermeiro. Mestrando em Enfermagem pela Universidade Federal do Rio Grande - PPGEnf FURG. Membro do GEPESES.

${ }^{4}$ Enfermeira. Doutoranda em Enfermagem pelo PPGEnf FURG. Professora da UNIFRA. Membro do Grupo de Estudo e Pesquisa: Gerenciamento Ecossistêmico em Enfermagem/Saúde - GEES.

${ }^{5}$ Enfermeira. Mestre em Enfermagem. Professora da UNIFRA. Membro do GEPESES.

${ }^{6}$ Enfermeira. Doutoranda em Enfermagem pelo PPGEnf FURG. Professora da UNIFRA. Membro do GEPESES.
}

Autor correspondente:

Hilda Maria Barbosa de Freitas

Centro Universitário Franciscano

Rua Felix Mainardi, 240 - 97110-633 - Santa Maria-RS-Brasil

E-mail: hildasame@gmail.com
Recebido: 06/05/2012 Aprovado: 20/08/2012 


\section{INTRODUÇÃO}

Atualmente, vive-se uma fase de mudança denominada transição epidemiológica, que consiste no aumento das doenças crônicas não transmissíveis. As condições crônicas constituem motivo de preocupação para os profissionais de saúde, por possuírem aspectos limitantes, devido às consequências de seu tratamento, desgaste $\mathrm{e}$ sofrimento da pessoa acometida ${ }^{(1)}$. Além disso, não se pode deixar de abordar os recursos financeiros e humanos dos serviços públicos e na demanda desses serviços, em que acabam sendo priorizadas atividades de cunho curativo e de reabilitação, em detrimento de ações de educação e promoção da saúde ${ }^{(2)}$.

A condição crônica pode ser considerada como experiência que envolve permanência e desvio do normal, causados por patologias que acarretam perdas e disfunções, além de permanente alteração no quotidiano das pessoas. Essa situação causa estresse devido à alteração da imagem corporal, necessidade de adequação social e psicológica, além de mudança na expectativa de $\operatorname{vida}^{(3)}$.

A Organização Mundial de Saúde define como doença crônica não transmissível as doenças cardiovasculares, neoplasias, doenças respiratórias crônicas e diabete mellitus. Nas condições crônicas, também se inclui as alterações que contribuem para o sofrimento do indivíduo, da família e da sociedade, como as de desordens mentais e neurológicas, bucais, ósseas e articulares, as genéticas e as patologias de ordem oculares e auditivas. Essas, conforme a Organização Pan-Americana de Saúde, ocorrem em países de baixa e média renda, em um percentual de $80 \%{ }^{(4)}$.

As transformações sociais e econômicas ocorridas no Brasil provocaram mudanças importantes no perfil de ocorrência das doenças da população. Estima-se que, até o ano de 2020, cerca de 388 milhões de pessoas evoluirão para óbito por condições crônicas, o que constitui motivo de preocupação para os profissionais de saúde, seja por seus aspectos limitantes ou pelas consequências das doenças crônicas ${ }^{(4)}$. Mais do que a simples preocupação dos profissionais, esses dados emergem para repensar estratégias que venham a contemplar, de forma efetiva, essa parcela da população, minimizando desta forma, os efeitos estressores da doença crônica, por meio de atividades pró ativas e empreendedoras.

No contexto atual da assistência à saúde, as famílias seguem assumindo a responsabilidade na prestação do cuidado à saúde de seus membros, especialmente aqueles com problemas crônicos, responsabilizando-se pela continuidade do cuidado, bem como, com as demais repercussões causadas pela doença ${ }^{(5)}$. Quando a doença afeta a criança/adolescente, o impacto do diagnóstico sobre a família envolve aspectos sociais, econômicos, afetivos e comportamentais, principalmente pela existência de complicações inerentes à patologia ${ }^{(1)}$.

Assim, a família, além de experienciar as crises e conflitos naturais do próprio ciclo de vida de seus membros, ainda enfrenta outras adversidades, como a condição crônica de um familiar, que necessita de olhar próximo e responsável dos profissionais de saúde. Nesses casos, a assistência precisa ser amiúde e efetiva, tendo em vista a melhoria da qualidade de vida da família como um todo, respeitando os direitos humanos e sociais ${ }^{(6)}$.

Neste delineamento, os grupos de Sala de Espera podem representar um território de trocas entre o indivíduo e o meio, em que os familiares podem interagir entre eles e com a equipe de saúde, fazendo com que, gradativamente, se efetive a educação em saúde por meio das vivências. Esse processo de educação em saúde auxilia os familiares para a responsabilidade do autocuidado, da promoção em saúde e do enfrentamento de ser cuidador de uma pessoa com condição crônica.

Corroborando com essa ideia, os profissionais de saúde, ao acolher os acompanhantes enquanto aguardam o paciente na sala de espera, podem oferecer um momento de troca de informações pertinentes relacionadas às situações de saúde da pessoa com condição crônica. Assim, a formação de grupos em Sala de Espera torna-se aliada para essas discussões, vínculo entre o familiar e o profissional da saúde, além da troca de experiências semelhantes com os demais participantes do grupo.

Nesse aspecto, por ser uma profissão envolvida diretamente nos processos de educação e promoção em saúde, pode-se afirmar que o enfermeiro junto a sua equipe são fundamentais na construção da educação e promoção em saúde. Ao atuarem em sala de espera, eles serão multiplicadores e mediadores de saberes, amenizando dúvidas, ansiedades, frustrações, medos, angústias, assim como, ouvindo as expectativas de futuro frente à condição crônica. Desta forma, poderão orientar familiares, oportunizar momentos de reflexão e problematização que favoreçam a construção de relações humanas e efetivas no cuidado em saúde, tanto para os familiares, pacientes, quanto para os próprios profissionais de saúde ${ }^{(7)}$.

Este estudo possui relevância para a equipe de enfermagem nas questões do ensino, do cuidado e da pesquisa, uma vez que, ao manter o diálogo da equipe com os fa- 
miliares na sala de espera, o enfermeiro auxilia a família na expressão dos sentimentos e dificuldades relativos ao enfrentamento da doença crônica no seu filho. Para tanto, faz emergir questões relacionadas às necessidades de cuidado, atenção e comprometimento, que devem estar presentes no cotidiano dos serviços de saúde, necessitando ganhar atenção e espaço para discussão.

Desse modo, esta pesquisa tem a seguinte questão norteadora: quais as expectativas das mães que participam do Grupo de Sala de Espera frente à condição crônica do filho? Na expectativa de possibilitar novos olhares, interativos e comprometidos com o ser humano inserido em seu contexto real, objetiva-se com este estudo compreender a expectativa das mães que participam do grupo Sala de Espera frente à condição crônica do filho.

\section{MÉTODO}

Trata-se de uma pesquisa exploratória, descritiva de caráter qualitativo $^{(8)}$, realizada com as mães de crianças/ adolescentes com condição crônica de saúde, atendidos nos Laboratórios de Práticas em Saúde à comunidade do Centro Universitário Franciscano - UNIFRA, sendo uma média de vinte mães participantes do Grupo Sala de Espera.

Como critérios de inclusão estabeleceram-se: ser familiar/cuidador de criança/ adolescente com condição crônica, estar sendo atendido no laboratório de práticas em saúde à comunidade da UNIFRA de maneira assídua (algumas mães trazem seus filhos por um determinado período e por outro deixam de trazê-los) e estar em condições físicas e/ou psíquicas de responder aos questionamentos. Desta forma, todas as mães foram convidadas a participar do estudo, no entanto, apenas 15 aceitaram participar após a assinatura do Termo de Consentimento Livre e Esclarecido, e formaram o corpus deste estudo. A coleta de informações ocorreu nos meses de janeiro a abril de 2011, por meio de entrevista semiestruturada. Nessa entrevista os participantes são estimulados a definir as dimensões significantes de um fenômeno, destacando o que é relevante na vivência deles, em vez de considerar os fatos importantes para o pesquisador ${ }^{(9)}$.

A entrevista em questão contemplou três questões abertas: Como você se sente frente à condição crônica de seu filho? Diante desta situação, exponha as alterações que surgiram na família; Como está sendo para você participar do Grupo Sala de Espera? Os depoimentos foram analisados por categorização, relacionando as respostas que mais se repetiram para a discussão dos resultados, classificando os elementos por agrupamento entre os discursos comuns existentes. O método de análise de conteúdo ${ }^{(9)}$ foi o que mais se adequou à pesquisa, constituindo-se de três momentos: o primeiro consistiu em uma frequência com identificação das principais percepções dos entrevistados; o segundo analisou o conteúdo identificando as categorias que emergiram a partir dos depoimentos coletados; e o terceiro interpretou essas categorias, buscando compreender a vivência dos entrevistados, a partir da experiência da pesquisadora, e relacionando-a ao objetivo do estudo.

Manteve-se o sigilo e o anonimato dos participantes identificando-os pelo nome de flores. Este estudo foi aprovado pelo Comitê de Ética do UNIFRA, sob número 390.2010.2.

\section{RESULTADOS}

A partir dos depoimentos das mães de crianças/ adolescentes com condição crônica participantes do estudo e da existência de subsídios para a análise, emergiram quatro categorias, apresentadas a seguir:

\section{Adaptando-se a condição crônica do filho}

Ao serem questionadas sobre como se sentem frente à condição crônica do filho, as mães relataram que no início foi difícil, mas com o tempo tudo foi se organizando, conforme se observa nas falas abaixo:

Muitas vezes fragilizada pelas condições da sociedade, revoltada com o sistema por não ter acesso aos deficientes como deveria, mas tranquila em relação a filha, pois ela tem potencial. (Rosa)

No início bastante chateada, mas depois, temos que enfrentar o problema para ajudar ele. (Camélia)

Foi complicado aceitar, tive que aprender sobre a doença, mas depois foi tranquilo, porque ele teve muito progresso. (Hostência)

Com dificuldade pelo preconceito, comentários das pessoas e dos colegas. (Copo de leite)

Frustração, pois achava que isso nunca poderia acontecer comigo, mas depois se encarou normal. (Vitória Régia)

Percebe-se, nas falas, que a aceitação da condição crônica do filho foi difícil, por não estarem preparados 
para tal situação. Corrobora para este fato, a falta de acessibilidade e o preconceito da sociedade em relação ao que foge do considerado padrão de normalidade.

\section{União familiar frente à condição crônica do filho}

Embora com todas as alterações e adaptações em decorrência da condição crônica da criança/adolescente, as mães relataram que após o diagnóstico houve maior união de todos os membros familiares. A seguir as falas:

Mexeu demais com a família, mobilizou e uniu todos. (Rosa)

A família se uniu, só fez bem! Agora vivemos em função do seu bem estar. (Jasmim)

Só houve melhoras, todos ficaram mais unidos. Claro que temos momentos de conflitos como toda familia, mas no que diz respeito ao cuidado do [...] todos temos o mesmo objetivo: fazer ele muito feliz, mesmo com suas limitações. (Hortência)

A família se uniu mais e eu tive mais paciência. (Orquídea)

Com o tempo apresentamos uma força que nem imaginávamos que tínhamos. A família se uniu mais para cuidar dele. (Gérbera)

Com base nos relatos, nota-se que, após a descoberta da condição crônica da criança/adolescente, a união familiar favoreceu para o enfrentamento da situação. Durante os encontros do Grupo Sala de Espera, as mães, por serem em maior número as cuidadoras das crianças/adolescentes, afirmam que descobriram uma força que não sabiam que tinham.

\section{Condição crônica: alterando as rotinas no contexto familiar}

As mães, afirmaram que as limitações trazidas no cotidiano modificaram o processo de viver, interferindo nas atividades diárias, tais como trabalho, lazer, estudo, entre outras. Isso se confirma com os relatos a seguir:

Parei de estudar, restringiu o lazer e os gastos aumentaram. (Margarida)

Tudo mudou. Agora tudo é ele, ele é o centro das aten- ções, vivo em função dele e para ele. (Copo de leite)

Deixei de trabalhar e o pai não aceitou a situação no início. (Crisântemo)

Tudo mudou, parei de estudar e restringiu o lazer. (Hortência)

Agora que já me organizei consigo fazer as minhas atividades no intervalo do cuidado dele e procuro sair, caminhar e levo sempre ele junto, precisa se adaptar no mundo, na sociedade, mesmo sabendo que as pessoas ficam olhando e perguntando o que ele tem. (Violeta)

Nas falas, evidencia-se o quanto à condição crônica modifica os hábitos da família, comprometendo, as rotinas e atividades de lazer de todos os envolvidos. No caso dos integrantes do estudo, outras perdas foram relatadas, como a necessidade de parar de trabalhar, a fim de direcionar a atenção à criança/adolescente, e o aumento dos gastos. Associado a isso, em alguns casos, o filho com condição crônica sofre rejeição por parte de alguns familiares.

\section{Sala de espera: troca de experiência e cuidado de enfermagem}

Em relação à participação no Grupo Sala de Espera, as mães afirmaram que este ambiente tem colaborado para troca de experiências, emergindo maior conhecimento e aceitação. Como é possível observar nas falas:

No início eu fugia, mas agora vejo que me ajudou muito, a gente vê o problema dos outros e troca experiências. (Orquídea)

É bom porque se conversa de tudo e nós nos ajudamos trocando experiências. Saber que posso contar com os profissionais que cuidam do meu filho, me dá segurança. Quando a enfermeira e a assistente social não estão na sala saio atrás para encontrá-las e conversar um pouquinho. (Copo de leite)

O tempo passa rápido, o conhecimento aumenta e se trocam experiências. Vejo que não sou a única mãe que sofre as limitações do filho. (Vitória régia)

Para mim e meus familiares tem sido indispensável esses encontros, aqui aprendi a me cuidar e assim cuidar melhor de meu filho. É importante saber que 
tem profissionais que pensam em nós, como vocês. (Gérbera)

As falas traduzem a finalidade do grupo em socializar as dificuldades e dúvidas dos participantes, que vivenciam situações semelhantes. O grupo emerge como facilitador no enfrentamento das mães frente à condição crônica de seus filhos, em que as mães experientes compartilham, com as mais novas, ou menos experientes, meios de enfrentar situações que surgem, com o cuidado diário de pacientes com condição crônica.

\section{DISCUSSÃO}

A aceitação da condição crônica por parte das mães é percebida neste estudo como um processo com diferentes momentos: primeiro, a disposição de aprender, que exige tomar conhecimento do que não sabe; segundo, a observação cuidadosa do que acontece na sociedade, estando atento ao que ocorre no dia-a-dia. Em terceiro, o respeito pela situação e a aceitação da condição em que se encontra, enfrentando-a; e quarto, o momento em que a aceitação se torna parte da própria pessoa, encara-se e vive-se a situação, é o momento em que as mães têm convicção da situação.

Esses resultados corroboram com os descritos em outro estudo que trata da internação de crianças e os sentimentos dos familiares. Para os familiares que acompanham a criança com doença crônica, este momento representa, inicialmente, uma desordem emocional, pelo medo do desconhecido e necessidade de se adaptar a uma nova realidade. $\mathrm{O}$ estudo em questão demonstrou que é fundamental a aceitação e torna-se imprescindível que os profissionais, em especial os que compõem a equipe de enfermagem, reconheçam a importância dos vínculos com a criança/adolescente e do cuidado com a família, tendo dedicação, atenção e, principalmente, a inter-relação dos saberes e fazeres, a fim de auxiliar no enfrentamento e adaptação a esta nova situação ${ }^{(7)}$.

Após a aceitação da condição do filho, a mãe exerce um papel importante no tratamento e recuperação do mesmo, colaborando para minimizar a ansiedade, o que, por sua vez, contribui para uma intervenção profissional mais efetiva e humana ${ }^{(10)}$. Neste aspecto, evidenciou-se neste estudo que aceitação da condição crônica do filho denota a compreensão de que as mudanças na vida da criança/adolescente com condição crônica e de sua família não englobam apenas alterações orgânicas ou físicas, sendo as emocionais e sociais de extrema relevância, as quais exigem constantes cuidados e adaptações.
A família pode apresentar despreparo psicológico para enfrentar a condição crônica, quando ocorrida na infância, o que acaba prejudicando a sua adaptação e a da criança, pois a família é o ponto de apoio para o fortalecimento e crescimento do portador de condição crônica, uma vez que colabora diretamente nas transformações de conceitos e comportamentos ${ }^{(6)}$. Como visto no estudo, a união familiar auxiliou as famílias e as crianças/ adolescentes no enfrentamento desta condição. Esse fato foi evidenciado também em um estudo desenvolvido sobre o enfrentamento das famílias de crianças com desordens crônicas, onde se evidenciou que a conduta harmoniosa, a integridade e o ajustamento familiar contribuíam, diretamente, no processo de recuperação e enfrentamento da condição crônica, tanto da criança/ adolescente quanto dos familiares ${ }^{(11)}$.

Quando se discute a doença crônica, é inviável pensar somente nos aspectos que influenciam diretamente a pessoa acometida. A doença faz parte do contexto familiar e assim, modifica as relações de todos os seus membros ${ }^{(12)}$. Neste aspecto, é possível perceber que as mães participantes do estudo vêem suas vidas envolvidas pela condição crônica e esse envolvimento reflete uma necessidade de atenção especial, alterando a rotina da família.

As falas evidenciam, ainda, que uma das mudanças decorrentes em relação à condição crônica no núcleo familiar refere-se ao abandono do trabalho em prol do cuidado da criança/adolescente. Esse caso evidenciou-se também em um estudo realizado em Ribeirão Preto, no qual os achados evidenciaram que as mães, deixam o trabalho profissional para segundo plano, ao se defrontarem com a necessidade de cuidar do filho. Sua dedicação ao cuidado impede o exercício de atividades externas, pois acaba não tendo como dividir o tempo entre as duas atividades ${ }^{(13)}$.

No decorrer deste estudo, percebeu-se que a maior necessidade das famílias, com filhos em condições crônicas, pode ser sanada com a ajuda de outras famílias em situações semelhantes e também pela equipe de enfermagem. Assim, apreende-se que o trabalho em grupo oportuniza o compartilhamento de conhecimentos advindos das experiências de cada envolvido. É por meio de trocas, que todos se beneficiam, encontrando respostas para as dúvidas, fazendo com que gradativamente se efetive a educação em saúde por meio dos grupos de apoio ${ }^{(7,14)}$.

Nesse aspecto, o Grupo Sala de Espera tem o intuito de contribuir para o cuidado humanizado, efetivando a aproximação cada vez maior entre a comunidade e os 
serviços de saúde. É por meio dela que os profissionais da saúde têm a oportunidade de desenvolver cuidado multidimensional, como a educação e a promoção da saúde, proporcionando melhora na qualidade do atendimento.

Neste delineamento, o enfermeiro tem o papel de cuidador e mediador do familiar, bem como da criança/adolescente com condição crônica, orientando e esclarecendo dúvidas e anseios, procurando efetivar escuta atenta e comprometida com o cuidado em saúde. No que tange a aprendizagem, pode-se dizer que ela é inerente ao processo de adaptação e indispensável para que as pessoas tenham acesso às possibilidades de escolha, conforme o contexto vivenciado ${ }^{(15)}$.

\section{CONCLUSÕES}

No estudo, pode-se perceber por meio dos relatos das mães, a situação de fragilidade das famílias que possuem crianças/adolescentes com condições crônicas. O diagnóstico da situação crônica dos filhos foi vivenciado pelas mães, com frustração e difícil aceitação, pois as mesmas relataram a falta despreparo para receber uma criança com essas condições. O tempo de convivência e o posterior estudo sobre as patologias são aliados para a superação e melhoria na qualidade de vida de todos.

Evidenciou-se a união familiar como alicerce para o enfrentamento da condição crônica da criança/adolescente, o que resultou na superação das dificuldades, e a contribuição do Grupo Sala de Espera pela troca de experiências e vivências de cada família, emergindo em maior conhecimento sobre as diversas patologias crônicas e maior aceitação. Como potencialidades, as mães afirmam que as dificuldades geradas pela condição crônica do filho acarretou maior união familiar e favoreceu a descoberta de uma força que elas até o momento desconheciam.

Nesse contexto, foi possível perceber que a educação em saúde em grupos de convivência, pôde contribuir para melhoraria na qualidade de vida das famílias que convivem com tal condição. Para tanto, torna-se imprescindível o fomento de mais estudos e discussões a respeito de atividades empreendedoras e inovadoras como os Grupos Sala de Espera, bem como mais atenção às famílias que possuem um de seus membros com condição crônica.

Destaca-se ainda, que as condutas profissionais, sejam de enfermagem ou de outras categorias profissionais, ou ainda, interdisciplinarmente, devem contemplar não apenas o amenizar das dores físicas, mas a compreensão, aceitação e bom convívio das famílias e das crianças/ adolescentes com condição crônica.

\section{REFERÊNCIAS}

1. Souza IVB de, Marques DKA, Lacerda ORM, Collet N. Percepção das mães frente ao diagnóstico do filho com diabetes mellitus tipo. Cogitare enferm. [Internet] 2011;16(1). [acesso em 05 jul 2011]. Disponível: http://ojs.c3sl.ufpr.br/ojs2/index.php/cogitare/article/ viewFile/21110/13936

2. Marconi SS, Radovanovic CAT, Waidman MAP, Oliveira MLF, Sales CA. Vivência e reflexões de um grupo de estudos junto às famílias que enfrentam a situação crônica de saúde. Texto Contexto Enferm. [Internet] 2005;14 (n. especial). [acesso em 20 jun 2011]. Disponível: http://www.scielo.br/pdf/tce/v14nspe/ a14v14nspe.pdf

3. Freitas MC, Mendes MMR. Condição crônica: análise do conceito no contexto da saúde do adulto. Rev. LatinoAm. Enfermagem. [Internet] 2007;15(4). [acesso em 20 jun 2011]. Disponível: http://www.scielo.br/pdf/rlae/ v15n4/pt_v15n4a11.pdf

4. Brasil. Ministério da saúde. Secretaria de Vigilância à Saúde. Secretaria de Atenção a Saúde. Diretrizes e Recomendações para o cuidado integral de doenças crônicas não transmissíveis: promoção da saúde, vigilância, prevenção e assistência. Brasília: Ministério da Saúde; 2008.

5. Freitas ICC, Paula KCC, Soares JL, Parente ACM. Convivendo com o portador de Alzheimer: perspectivas do familiar cuidador. Rev Bras Enferm. [Internet] 2008;61(4). [acesso em 20 jun 2011]. Disponível: http:// www.scielo.br/pdf/reben/v61n4/18.pdf

6. Moraes SDTA, Buchalla CM, Valenti VE, Leite L, Tanaka ACA, Macedo Júnior H, et al. Acolhendo o acolhedor: o caminho mais curto para a humanização da assistência. Rev. bras. crescimento desenvolv. hum. [Internet] 2009;19(3) [acesso em 05 jul 2011]. Disponível: http://www.revistasusp.sibi.usp.br/pdf/ rbcdh/v19n3/06.pdf

7. Mariano LRA, Backes DS, Ilha S, Nicola GDO, Freitas HMB de, Ferreira CLL de. Significado da internação hospitalar pediátrica na perspectiva de profissionais e familiares. Cogitare enferm. [Internet] 2011;16(3). [acesso em 10 out 2011]. Disponível: http://ojs.c3sl.ufpr.br/ojs2/index.php/cogitare/article/ view/24224

8. Polit DF, Beck CT, Hungler BP. Fundamentos de pesquisa em enfermagem: métodos, avaliação e utilização. $5^{\mathrm{a}}$ ed. Porto Alegre: Artes Médicas; 2004. 
9. Bardin L. Análise de conteúdo. $4^{\mathrm{a}}$ ed. Lisboa: Edições 70. 2009.

10. Francioni FF. Grupo de convivência: uma alternativa para o processo de aceitação do viver com diabetes mellitus. [dissertação]. Florianópolis (SC): Universidade Federal de Santa Catarina; 2002.

11. Araújo YB de, Collet N, Moura FM de, Nóbrega RD da. Conhecimento da família acerca da condição crônica na infância. Texto Contexto Enferm. [Internet] 2009;18(3). [acesso em 20 jul 2011]. Disponível: http://www.scielo. br/pdf/tce/v18n3/a13v18n3.pdf

12. Silva MAS, Collet N, Silva KL, Moura FM. Cotidiano da família no enfrentamento da condição crônica na infância. Acta Paul. Enferm. [Internet] 2010;23(3). [acesso em 20 jul 2011]. Disponível: http://www.scielo. br/pdf/ape/v23n3/v23n3a08.pdf

13. Anders JC. A família na assistência à criança e ao adolescente submetidos ao transplante de medula óssea: fase pós-TMO. [dissertação]. Ribeirão Preto (SP): Universidade de São Paulo; 1999.

14. Souza AC, Colomé ICS, Costa LED, Oliveira DLLC. A educação em saúde com grupos na comunidade: uma estratégia facilitadora da promoção da Saúde. Rev Gaúcha Enferm. [Internet] 2005;26(2). [acesso em 20 jun 2011]. Disponível: http://seer.ufrgs.br/ RevistaGauchadeEnfermagem/article/view/4547

15. Dall'Agnol CM, Resta DG, Zanatta E, Schrank G, Maffacciolli R. O trabalho com grupos como instância de aprendizagem em saúde. Rev. Gaúcha Enferm. [Internet] 2007;28(1). [acesso em 05 ago 2011]. Disponível: http:// seer.ufrgs.br/RevistaGauchadeEnfermagem/article/ view/4690 